\title{
Alcohol use and associated factors among women attending antenatal care in Southern Ethiopia: a facility based cross sectional study
}

\author{
Birhanie Mekuriaw ${ }^{1 *} \mathbb{D}$, Zelalem Belayneh ${ }^{1}$, Tinsae Shemelise ${ }^{2}$ and Robel Hussen ${ }^{2}$
}

\begin{abstract}
Objectives: The aim of this study was to assess the prevalence and associated factors of alcohol use among women attending Antenatal Care in Gedeo zone rural health centers (Southern Ethiopia). This was a cross-sectional study conducted among randomly selected 718 pregnant women attending Antenatal Care. Alcohol Use Disorder Identification Test- $C$ was used to assess alcohol consumption. Variables with $p$-values of $<0.05$ in the multivariable logistic regression were considered as having a statistically significant association with alcohol use.

Results: The prevalence of alcohol use among pregnant women attending antenatal care service was $8.1 \%$ with $95 \% \mathrm{Cl}(6.3-10.0)$. Unplanned pregnancy $[\mathrm{AOR}=2.12,95 \% \mathrm{Cl}(1.20,3.73)]$, abortion history $[\mathrm{AOR}=2.40,95 \% \mathrm{Cl}(1.16$, 4.96)], pre pregnancy alcohol use $[\mathrm{AOR} 2.17,95 \% \mathrm{Cl}(1.18,4.00)]$ and mental distress $[\mathrm{AOR}=3.50,95 \% \mathrm{Cl}(1.99,6.15)]$ were variables found to have a statistically significant association with alcohol use. This calls a holistic and multi modal approach for the prevention, early identification and intervention of alcohol use during pregnancy. More emphasis should also be given for pregnant women with unplanned pregnancy, history of abortion, pre pregnancy alcohol use and mental distress.
\end{abstract}

Keywords: Alcohol use, Pregnancy, Women, Anti natal Care, Gedeo zone, Harm full drinking

\section{Introduction}

A couple of decades have been counted since alcohol use is identified as a global burden of disease with mortality rate of more than chronic medical conditions like HIV and tuberculosis [1]. Alcohol consumption has been identified as a critical problem among pregnant women and child bearing mothers dating back to very ancient time. This can significantly affect the health status of both the mother and her babies in almost all socioeconomic groups $[2,3]$.

Studies showed that binge alcohol drinking (drinking five and above units of drink in one occasion) is harmful for the mother and the developing fetus due to the

\footnotetext{
*Correspondence: biradilla@gmail.com

${ }^{1}$ Department of Psychiatry, College of Health and Medical Science, Dilla University, Dilla, Ethiopia

Full list of author information is available at the end of the article
}

destructive or teratogenic effects as well as higher vulnerability of fetal alcohol spectrum disorders $[4,5]$. Although multiple clinical recommendations and public health campaigns are invested regarding the problems of alcohol use during pregnancy, evidences showed that pregnant women continue to consume alcohol across the world, particularly in low-income countries like Ethiopia [6-8].

World health organization (WHO) estimates the prevalence of alcohol consumption during pregnancy as 7.9\% and 3.4-20.5\% in Ethiopia and east Africa, respectively [7]. The prevalence of alcohol use among pregnant women was reported to be $15.1 \%$ in Tanzania [9], 34\% in Ethiopia [10], 59.3\% in Nigeria [11] and 20.4\% in Ghana [12]. Partner alcohol drinking, multi parity, unplanned pregnancy, partner violence, history of still birth, abortion history and poor social support were some of the 
factors contributing for alcohol use during pregnancy [9, $10,12-14]$.

Literatures also revealed that women might use alcohol as a coping mechanism to escape from pregnancy related stressful situations and emotional instability $[15,16]$. The drinking habits of alcohol can be also determined by the culture, attitude or other socio-demographic contexts of the society in which the pregnant mother belongs [17, 18].

In Ethiopia, there are different locally made and culturally accepted alcoholic beverages (Tella, Tej, Areki, wine....) with different alcoholic contents. These alcoholic beverages are commonly consumed in daily basis during meals. Thus, people use such easily accessible and culturally acceptable beverages in different parties, ceremonies and even, in daily family meals $[19,20]$.

However, little is known regarding the prevalence and associated factors of alcohol use among pregnant women attending ANC service. Therefore, it is vital to screen alcohol use and identify its associated factors among women attending ANC service at rural health centers.

\section{Main text \\ Methods \\ Study design and period}

This was an institutional based cross sectional study conducted among women attending antenatal care in Gedeo zone rural health centers from June 1st to August 1st 2017.

\section{Study setup}

The study was conducted at Gedeo zone rural health centers. Gedeo zone is found in Southern Nation Nationalities and Peoples Regional (SNNPR) states of Ethiopia at $359 \mathrm{~km}$ Sothern from Addis Ababa (the capital city of Ethiopia). The total population size of the zone is 847,434 (424,742 male and 422,692 female) according to the 2007 population and housing census [21]. There are about 41,733 pregnant women estimated to initiate ANC1 within rural health centers of the zone annually.

\section{Sample size and sampling technique}

The sample size was determined using a single population proportion formula. We used assumptions of prevalence of alcohol use $(\mathrm{p}=34 \%)$ from a study done in North-west part of Ethiopia (Bahir Dar) [10], 5\% margin of error and 95\% confidence interval. Considering 10\% non response rate and design effect of two, the total sample size was 759.

Two-stage sampling technique was used to select study subjects. First, four woredas were randomly selected from a total of six woredas and two city administrations. In the second stage, two health centers were selected from each of the selected four woredas through lottery method. Then, the calculated sample size was proportionally allocated to each of eight randomly selected health centers. Finally, pregnant women attending ANC service were interviewed consecutively until the allocated sample size was addressed.

\section{Data collection procedures and instruments}

A pre-tested interviewer administered questionnaire was used for the data collection. The questionnaire had different components including socio demographic characteristics, obstetric and gynecological factors, substance related variables, Oslo-3 Social Support Scale, Self Reporting Questionnaire (SRQ-20) and Alcohol Use Disorder Identification Test-C (AUDIT-C).

Alcohol use was measured using AUDIT-C [22, 23] derived from the 10-item alcohol use disorder identification test which is cross culturally validated and preferred tool to measure alcohol consumption [24, 25]. AUDIT-C has been used in different studies to measure alcohol use among pregnant women [9, 26, 27]. It has three Likert scale questions used to evaluate the frequency and quantity of alcohol intake. AUDIT-C has a total sum score of 12 which can be categorized as low risk (1-3), moderate risk (4-5) and high risk $(\geq 6)$. The questions of AUDIT$\mathrm{C}$ were adapted for pregnancy and contextualized for the study area. In this study, women with sum scores of greater and equal to three were considered alcohol user.

Level of social support was assessed using Oslo-3 item Social Support Scale having a maximum sum score of 14 . The sum scores were categorized as poor $(0-3)$, moderate (9-11) and strong (12-14) [28]. An Ethiopian validated Self Reporting Questionnaire (SRQ-20) was used to screen mental distress. It shows god accuracy to screen mental distress in primary health care settings and communities of low-income countries with a cut-off point of 7 and above [29].

The questionnaire was first prepared in English and translated to Amharic and Gedeou'fa (commonly spoken languages in the study area). Back translation to English was done to check its consistency. Pre test was done on $5 \%(n=43)$ of the sample among women attending ANC service at Chucko heath center. The data were collected by nine degree level health professionals supervised by three masters level public health professionals after attending 3 days of training regarding the contents of the questionnaire and data collection procedures.

\section{Data analysis}

First, the collected data were checked for its completeness and consistency and entered to Epi-INFO (software). Then, the data were exported to a Statistical Package for Social Science (SPSS-version 20) for analysis. Descriptive 
analysis was used to determine the prevalence of alcohol use and its distribution among the characteristics of participants. Both bivariable and multivariable binary logistic regression were computed to identify factors associated with alcohol use. Variables with p-values of $\leq 0.25$ in the bivariable analysis were considered as candidates for multivariable regression to control possible confounders. In the final model, variables with p-values of $<0.05$ were considered as having a statistically significant association with alcohol use at a corresponding $95 \% \mathrm{CI}$.

\section{Results}

\section{Socio-demographic characteristics}

Among a total of 759 women invited to participate, 718 completed the interview with a response rate of $94.6 \%$. More than half, $(53.5 \% ; \mathrm{n}=384)$ of participants were within the age range of 25-29 years old and the mean (standard deviation) age of respondents was $27.1( \pm 4.23)$ year. Large proportion, (77.6\%; $\mathrm{n}=557$ ) of participants were married and living together. More than half (57.4\%; $\mathrm{n}=412$ ) of the participants were Gedeo in ethnicity (Table 1).

\section{Obstetrics and psychosocial factors}

Regarding the gestational age, 52.2\% $(\mathrm{n}=375)$ were within the third trimester. Of the total participants, $19.2 \%$ $(\mathrm{n}=142)$ had pre pregnancy alcohol use history. About $26.2 \%(n=188)$ of participants were screened positive for mental distress (Table 2).

\section{Prevalence and associated factors of alcohol use}

The overall prevalence of alcohol use was found to be $8.1 \%(\mathrm{n}=58)$ with $95 \%$ CI $(6.3,10.0)$. During bivariable regression, age, place of residency, number of children, pregnancy plan, pre pregnancy alcohol use, abortion history, khat chewing, mental distress and level of social support were variables associated with alcohol use. After adjusting for possible confounders, unplanned pregnancy, abortion history, pre pregnancy alcohol use and mental distress were found to have a statistically significant association with alcohol use (Table 3).

\section{Discussion}

The prevalence of alcohol use was found to be $8.1 \%$ $(\mathrm{n}=58)$ with $95 \%$ CI (6.3\%-10.0\%). The magnitude of alcohol use in this study was in line with WHO estimate of alcohol use during pregnancy in Ethiopia(7.9\%) [7]. However, the prevalence of alcohol use in this study was lower than the prevalence of alcohol use reported from a study of Northwest Ethiopia (34\%) [10]. The possible explanation for this difference might be due to the difference in the screening tools used. The study
Table 1 Socio-demographic characteristics of pregnant women attending Ante Natal Care in Gedeo Zone Health Centers, Southern Ethiopia, $2017(n=718)$

\begin{tabular}{|c|c|c|c|}
\hline Variables & Categories & Frequency & Percentage \\
\hline \multirow[t]{4}{*}{ Age in years } & $\leq 20$ & 42 & 5.8 \\
\hline & $21-24$ & 155 & 21.6 \\
\hline & $25-29$ & 384 & 53.5 \\
\hline & $\geq 30$ & 137 & 19.1 \\
\hline \multirow[t]{2}{*}{ Marital status } & Married & 557 & 77.6 \\
\hline & Single & 161 & 22.4 \\
\hline \multirow[t]{4}{*}{ Religion } & Protestant & 413 & 57.5 \\
\hline & Orthodox & 201 & 28.0 \\
\hline & Muslim & 73 & 10.2 \\
\hline & Others $^{\mathrm{a}}$ & 31 & 4.3 \\
\hline \multirow[t]{5}{*}{ Ethnicity } & Gedeo & 412 & 57.4 \\
\hline & Wolaita & 93 & 13.0 \\
\hline & Gurage & 83 & 11.6 \\
\hline & Oromo & 86 & 12.0 \\
\hline & Others $^{b}$ & 44 & 6.1 \\
\hline \multirow[t]{2}{*}{ Residency } & Urban & 326 & 45.4 \\
\hline & Rural & 392 & 54.6 \\
\hline \multirow[t]{5}{*}{ Occupation } & Farmers & 241 & 33.6 \\
\hline & Employed & 166 & 23.1 \\
\hline & Merchant & 121 & 16.9 \\
\hline & House wife & 68 & 9.5 \\
\hline & Others ${ }^{c}$ & 122 & 17.0 \\
\hline \multirow[t]{5}{*}{ Educational level } & $\begin{array}{l}\text { Unable to read and } \\
\text { write }\end{array}$ & 218 & 30.4 \\
\hline & $\begin{array}{l}\text { Able to read and } \\
\text { write }\end{array}$ & 171 & 23.8 \\
\hline & Primary school & 125 & 17.4 \\
\hline & Secondary school & 109 & 15.2 \\
\hline & College and above & 95 & 13.2 \\
\hline \multirow{4}{*}{$\begin{array}{l}\text { Monthly income in } \\
\text { ETB }\end{array}$} & $\leq 500$ & 147 & 20.5 \\
\hline & $501-999$ & 159 & 22.1 \\
\hline & 1000-1999 & 332 & 46.2 \\
\hline & $\geq 2000$ & 80 & 11.1 \\
\hline
\end{tabular}

\footnotetext{
a Other religions-catholic and wakifeta

b Other ethnicities-Amhara and Sidama

c Other occupations-daily laborer and students
}

conducted in Bahir-Dare used "T-ACE" which is more sensitive than AUDIT-C to screen alcohol use and might overestimate the prevalence [26]. In addition, the study conducted at Bahir-Dare was a community based study that can address all pregnant women, even not attending ANC follow-up. However, our study included only pregnant women attending ANC clinic. Inclusion of only pregnant women attending ANC clinic might yield a lower prevalence of alcohol use as women attending ANC can have the opportunity of counseling service, and may gain better knowledge and attitude 
Table 2 Obstetric, substance and psychosocial related factors among pregnant women attending Ante Natal Care in Gedeo Zone Health Centers, Southern Ethiopia, $2017(n=718)$

\begin{tabular}{llll}
\hline Variables & Categories & Frequency & Percentage \\
\hline Gestational age & First trimesters & 121 & 16.9 \\
& Second trimesters & 22 & 30.9 \\
& Third trimesters & 375 & 52.2 \\
No. of children & No child yet & 298 & 41.5 \\
& Has one child & 127 & 17.7 \\
& Has two child & 133 & 18.5 \\
Abortion history & Has three and more & 160 & 22.3 \\
& Yes & 82 & 11.4 \\
History of still birth & No & 636 & 88.6 \\
& Yes & 69 & 9.6 \\
Alcohol use before & No & 649 & 90.4 \\
pregnancy & Yes & 142 & 19.2 \\
Partner alcohol use & Yes & 576 & 80.8 \\
& No & 377 & 46.9 \\
Current khat chewing & No & 381 & 53.1 \\
& Yes & 647 & 90.1 \\
Information regarding & Yes & 71 & 9.9 \\
substance problem & No & 115 & 16.0 \\
Mental distress & Negative & 603 & 84.0 \\
Social support level & Positive & 530 & 73.8 \\
& Poor & 232 & 26.2 \\
& Moderate & 237 & 32.3 \\
& Strong & 249 & 34.7 \\
\hline
\end{tabular}

towards the health of the fetus and themselves. Furthermore, women with substance use including alcohol might under report their consumption while they are at ANC service due to the fear of breaking professional advice of "not taking any alcohol during pregnancy". The prevalence of alcohol use in this study was also lower than other studies of Tanzania (15.1\%) [9], Ghana (20.4\%) [12] and Nigeria (59.3\%) [11]. The possible reason for this discrepancy might be due to the differences of screening tools used to measure alcohol use as well as the cultural and socio-demographic variation of study participants.

This study also identified correlates of alcohol use among women attending ANC service. Accordingly, unplanned pregnancy, pre pregnancy alcohol use, abortion history and mental distress were found to have a statistically significant association. The odds of alcohol use among women with unplanned pregnancy were 2.1 times higher as compared to their counterparts. This is consistent with other studies of Bahir-Dare and Korea [10, 27]. The possible explanation for this correlation might be due the social and psychological crisis of unplanned pregnancy that can have a potential to push pregnant women for the initiation of alcohol or other substance use to get relief from their stress [30].

Similarly, the odds of having alcohol use among pregnant women who had pre pregnancy alcohol use history were 2.2 times higher than women who had not history of alcohol use before their current pregnancy. This finding is in agreement with a recent review and another similar study which identified pre pregnancy alcohol use as a precipitant for alcohol consumption during pregnancy $[14,27]$. Moreover, the brain rewarding systems of alcohol has a tendency to develop dependency which might be difficult to abstain or decrease drinking, and enforce to search alcoholic beverages even during pregnancy period [31]. Pregnant women who had history of abortion had 2.4 times increased odds of being alcohol user as compared to women who had not abortion history. This might be explained by the fact that previous abortion can elevate rates of substance use and other mental health problems like depression and anxiety [32]. However, a study conducted in Tanzania showed a reverse result indicating complications in previous pregnancy as a protective factor of alcohol use during pregnancy [9]. The possible reason for this discrepancy might be due to the fact that some women may associate previous pregnancy complications with the negative effect of alcohol that might help them to cease drinking for their future pregnancy. On the contrary, others pregnant women may develop psychological distress following pregnancy related complication which can push them to use alcohol to escape from stressful situation. Furthermore, it needs further investigation in this regard.

Pregnant women with mental distress were 3.5 times more likely to use alcohol as compared to their counterparts. This might be due to the fact that people with mental distress are more like to use alcohol to reverse the difficulties of sleep initiation, social engagement and lack of happiness which are hallmark symptoms of mental distress [33, 34].

\section{Limitations of the study}

Participants were recruited from ANC clinics which might not be representative for women who do not attend ANC. Therefore, further community based study 
Table 3 Variables associated with alcohol use among pregnant women attending Ante Natal Care in Gedeo Zone Health Centers, Southern Ethiopia, 2017

\begin{tabular}{|c|c|c|c|c|c|}
\hline \multirow[t]{2}{*}{ Variables } & \multicolumn{2}{|c|}{ Alcohol use status } & \multirow[t]{2}{*}{ COR $(95 \% \mathrm{Cl})$} & \multirow[t]{2}{*}{ AOR $(95 \% \mathrm{Cl})$} & \multirow[t]{2}{*}{ p-value } \\
\hline & Yes & No & & & \\
\hline \multicolumn{6}{|l|}{ Ages in years } \\
\hline$\leq 20$ & $5(11.9 \%)$ & 37 (88.1\%) & 1.00 & 1.00 & 1.00 \\
\hline $21-24$ & $9(5.8 \%)$ & $146(94.2 \%)$ & $0.45(0.14-1.44)$ & $0.50(0.14-1.73)$ & 0.280 \\
\hline $25-29$ & $32(8.3 \%)$ & $352(91.3 \%)$ & $0.67(0.24-1.83)$ & $0.74(0.25-2.19)$ & 0.580 \\
\hline$\geq 30$ & $12(8.8 \%)$ & $125(91.2 \%)$ & $0.71(0.23-2.14)$ & $0.78(0.23-2.60)$ & 0.680 \\
\hline \multicolumn{6}{|l|}{ Residency } \\
\hline Urban & $34(10.4 \%)$ & $292(89.6 \%)$ & $1.78(1.03-3.07)$ & $1.71(0.97-3.01)$ & 0.062 \\
\hline Rural & $24(6.1 \%)$ & $368(93.9 \%)$ & 1.00 & 1.00 & 1.00 \\
\hline \multicolumn{6}{|l|}{ Pregnancy plan } \\
\hline Planned & $27(6.0 \%)$ & $424(94.0 \%)$ & 1.00 & 1.00 & 1.00 \\
\hline Unplanned & $31(11.6 \%)$ & $236(88.4 \%)$ & $2.06(1.20-3.54)$ & $2.12(1.20-3.73)$ & $0.007^{*}$ \\
\hline \multicolumn{6}{|l|}{ No of children } \\
\hline No children yet & $17(5.7 \%)$ & $281(94.3 \%)$ & 1.00 & 1.00 & 1.00 \\
\hline Has one child & $13(10.2 \%)$ & $114(89.8 \%)$ & $1.88(0.88-4.00)$ & $1.74(0.78-3.86)$ & 0.169 \\
\hline Has two child & $13(9.8 \%)$ & $120(90.2 \%)$ & $1.79(0.84-3.80)$ & $1.33(0.60-2.96)$ & 0.471 \\
\hline Three and more & $15(9.4 \%)$ & $145(90.6 \%)$ & $1.71(0.83-3.52)$ & $1.67(0.77-3.62)$ & 0.190 \\
\hline \multicolumn{6}{|l|}{ Abortion history } \\
\hline Yes & $12(14.6 \%)$ & $0(85.4 \%)$ & $2.19(1.11-4.34)$ & $2.40(1.16-4.96)$ & $0.018^{*}$ \\
\hline No & $46(7.2 \%)$ & $590(92.8 \%)$ & 1.00 & 1.00 & 1.00 \\
\hline \multicolumn{6}{|c|}{ Pre pregnancy alcohol use } \\
\hline Yes & $19(13.4 \%)$ & $123(86.6 \%)$ & $2.12(1.18-3.80)$ & $2.17(1.17-4.00)$ & $0.013^{*}$ \\
\hline No & $39(6.8 \%)$ & $537(93.2 \%)$ & 1.00 & 1.00 & 1.00 \\
\hline \multicolumn{6}{|l|}{ Khat chewing } \\
\hline No & $46(7.1 \%)$ & $601(92.9 \%)$ & 1.00 & 1.00 & 1.00 \\
\hline Yes & $12(16.9 \%)$ & $59(83.1 \%)$ & $2.65(1.33-5.29)$ & $1.83(0.87-3.87)$ & 0.110 \\
\hline \multicolumn{6}{|l|}{ Mental distress } \\
\hline Negative & $29(5.5 \%)$ & $501(94.5 \%)$ & 1.00 & 1.00 & 1.00 \\
\hline Positive & $29(15.4 \%)$ & $159(84.6 \%)$ & $3.15(1.82-5.43)$ & $3.50(1.99-6.15)$ & $0.000^{*}$ \\
\hline \multicolumn{6}{|l|}{ Social support level } \\
\hline Poor & $21(9.1 \%)$ & $211(90.9 \%)$ & $1.55(0.78-3.09)$ & $1.49(0.72-3.05)$ & 0.275 \\
\hline Moderate & $22(9.3 \%)$ & $215(90.7 \%)$ & $1.59(0.80-3.15)$ & $1.40(0.67-2.90)$ & 0.360 \\
\hline Strong & $15(6.0 \%)$ & $234(94.0 \%)$ & 1.00 & 1.00 & 1.00 \\
\hline
\end{tabular}

* Significantly associated variables at $p$-value $<0.05,1.00$-References

is recommended to address the level of alcohol use among women who do not attend ANC service. The cross-sectional nature of the study design might not show the cause and effect relationships between alcohol use and other variables.

\section{Abbreviations}

ANC: antenatal care; AOR: adjusted odd ratio; Cl: confidence interval; AUDIT-C: Alcohol Use Disorder Identification Test-Consumption; COR: crude odd ratio; DURH: Dilla University Referral Hospital; ETB: Ethiopian Birr; SD: standard deviation; SRQ: Self Reporting Questionnaire; SSNPR: Southern Nation Nationalities and Peoples of Region; T-ACE: (Tolerance, Annoyed, Cut off and Eye opening); WHO: World Health Organization.

\section{Acknowledgements}

We are thankful towards study participants for investing their fruitful time to participate in this study. Our gratitude also goes to health care professionals serving for antenatal care in the rural health center of Gedeo zone for their unlimited support and cooperation. 


\section{Authors' contributions}

$\mathrm{BM}$ and $\mathrm{ZB}$ conceived the research question, participated in the proposal development, data collection, analysis, interpretation and critically reviewed the manuscript. TS participated during data collection, analysis and interpretation of the data. $\mathrm{RH}$ contributed to the analysis and manuscript preparation. All the authors read and approved the final manuscript.

\section{Funding}

Not applicable.

\section{Availability of data and materials}

All the data included in this manuscript can be accessed from the corresponding author Birhanie Mekuriaw upon request through the email address of "biradilla@gmail.com".

\section{Ethics approval and consent to participate}

This study was ethically approval by the Institutional Review Board (IRB) of Dilla University. Permission letter was also obtained from Gedeo Zone Health Bureau. The Interview was conducted privately after securing written consent from each participant. The information obtained from participants was kept confidential during all stages of the study, and used only for the purpose of the study.

\section{Consent for publication}

Not applicable.

\section{Competing interests}

The authors declare that they have no competing interests.

\section{Author details}

${ }^{1}$ Department of Psychiatry, College of Health and Medical Science, Dilla University, Dilla, Ethiopia. ${ }^{2}$ Department of Public Health, College of Health and Medical Science, Dilla University, Dilla, Ethiopia.

\section{Received: 8 Auqust 2019 Accepted: 3 October 2019}

\section{Published online: 24 October 2019}

\section{References}

1. Mathers C, Ayuso-Mateos JL. Global burden of alcohol use disorders in the Year 2000: summary of methods and data sources. In.: GBD 2000 Working Paper. Geneva: World Health Organization. http://www.who. 2003.

2. de Sanctis L, Memo L, Pichini S, Tarani L, Vagnarelli F. Fetal alcohol syndrome: new perspectives for an ancient and underestimated problem. J Matern Fetal Neonatal Med. 2011;24(sup1):34-7.

3. Abel EL. Maternal alcohol consumption and spontaneous abortion. Alcohol Alcohol. 1997;32(3):211-9.

4. Henderson J, Kesmodel U, Gray R. Systematic review of the fetal effects of prenatal binge-drinking. J Epidemiol Community Health. 2007;61(12):1069-73.

5. Ornoy A, Ergaz Z. Alcohol abuse in pregnant women: effects on the fetus and newborn, mode of action and maternal treatment. Int J Environ Res Public Health. 2010;7(2):364-79.

6. Casiro OG, Stanwick RS, Pelech A, Taylor V. Public awareness of the risks of drinking alcohol during pregnancy: the effects of a television campaign Child Health Committee, Manitoba Medical Association. Can J Public Health. 1994;85(1):23-7.

7. Popova S, Lange S, Probst C, Shield K, Kraicer-Melamed H, Ferreira-Borges C, Rehm J. Actual and predicted prevalence of alcohol consumption during pregnancy in the WHO African Region. Trop Med Int Health. 2016;21(10):1209-39.

8. Lange S, Probst C, Heer N, Roerecke M, Rehm J, Monteiro MG, Shield K, de Oliveira C, Popova S. Actual and predicted prevalence of alcohol consumption during pregnancy in Latin America and the Caribbean: systematic literature review and meta-analysis. Revista Panamericana de Salud Pública. 2017;41:e89.

9. Mpelo M, Kibusi SM, Moshi F, Nyundo A, Ntwenya JE, Mpondo BC. Prevalence and factors influencing alcohol use in pregnancy among women attending antenatal care in Dodoma region, Tanzania: a cross-sectional study. J Pregnancy. 2018;2018:8580318.

10. Anteab K, Demtsu B, Megra M. Assessment of Prevalence and Associated Factors of Alcohol Use during Pregnancy among the dwellers of BahirDar. City, Northwest Ethiopia. 2014;5:939.

11. Ordinioha B, Brisibe S. Alcohol consumption among pregnant women attending the ante. natal clinic of a tertiary hospital in South South Nigeria. Niger J Clin Pract. 2015;18(1):13-7.

12. Adusi-Poku Y, Edusei AK, Bonney AA, Tagbor H, Nakua E, Otupiri E. Pregnant women and alcohol use in the Bosomtwe district of the Ashanti region-Ghana. Afr J Reprod Health. 2012;16(1):55-60.

13. Culley CL, Ramsey TD, Mugyenyi G, Kiwanuka GN, Ngonzi J, MacLeod S, Koren G, Grunau BE, Wiens MO. Alcohol exposure among pregnant women in Sub-Saharan Africa: a systematic review. J Popul Therap Clin Pharmacol. 2013;20(3):321-33.

14. Skagerstrom J, Chang G, Nilsen P. Predictors of drinking during pregnancy: a systematic review. J Women's Health. 2011;20(6):901-13.

15. Biratu A, Haile D. Prevalence of antenatal depression and associated factors among pregnant women in Addis Ababa, Ethiopia: a cross-sectional study. Reprod Health. 2015;12(1):99.

16. Thompson O, Ajayi I. Prevalence of antenatal depression and associated risk factors among pregnant women attending antenatal clinics in Abeokuta North Local Government Area. Nigeria. Depression research and treatment. 2016;2016:4518979.

17. Peadon E, Payne J, Henley N. D'antoine H, Bartu A, O'Leary C, Bower C, Elliott EJ: attitudes and behaviour predict women's intention to drink alcohol during pregnancy: the challenge for health professionals. BMC Public Health. 2011;11(1):584.

18. Petersen Williams P, Jordaan E, Mathews C, Lombard C, Parry CD. Alcohol and other drug use during pregnancy among women attending midwife obstetric units in the Cape Metropole. South Africa. Adv Prev Med. 2014:2014:871427.

19. Soboka M, Tesfaye M, Feyissa GT, Hanlon C. Alcohol use disorders and associated factors among people living with HIV who are attending services in south west Ethiopia. BMC Res Notes. 2014;7(1):828.

20. Lee M, Regu M, Seleshe S. Uniqueness of Ethiopian traditional alcoholic beverage of plant origin, tella. J Ethnic Foods. 2015;2(3):110-4.

21. Ethiopia C: Summary and statistical report of the 2007 population and housing census. Addis Ababa: Federal democratic republic of Ethiopia population census commission; 2008. p. 1-10.

22. Lopez MB, Lichtenberger A, Conde K, Cremonte M. Psychometric properties of brief screening tests for alcohol use disorders during pregnancy in Argentina. Revista brasileira de ginecologia e obstetricia. 2017;39(7):322-9.

23. Bradley KA, Bush KR, Epler AJ, Dobie DJ, Davis TM, Sporleder JL, Maynard C, Burman ML, Kivlahan DR. Two brief alcohol-screening tests From the Alcohol Use Disorders Identification Test (AUDIT): validation in a female Veterans Affairs patient population. Arch Intern Med. 2003;163(7):821-9.

24. Saunders JB, Aasland OG, Babor TF, De la Fuente JR, Grant M. Development of the alcohol use disorders identification test (AUDIT): WHO collaborative project on early detection of persons with harmful alcohol consumption-II. Addiction. 1993;88(6):791-804.

25. Babor TF, Higgins-Biddle JC, Saunders JB, Monteiro MG: AUDIT: The alcoholuse disorders identification test. Guidelines for use in primary care. Geneva, Switzerland: World Health Organization, Department of Mental Health and Substance Dependence; 2001.

26. Smith L, Savory J, Couves J, Burns E. Alcohol consumption during pregnancy: cross-sectional survey. Midwifery. 2014;30(12):1173-8.

27. Lee SH, Shin SJ, Won SD, Kim EJ, Oh DY. Alcohol use during pregnancy and related risk factors in Korea. Psychiatry Investig. 2010;7(2):86-92.

28. Abiola T, Udofia O, Zakari M. Psychometric properties of the 3-item oslo social support scale among clinical students of Bayero University Kano, Nigeria. Malay J Psychiatry. 2013;22(2):32-41. 
29. Hanlon C, Medhin G, Alem A, Araya M, Abdulahi A, Hughes M, Tesfaye $M$, Wondimagegn $D$, Patel V, Prince M. Detecting perinatal common mental disorders in Ethiopia: validation of the self-reporting questionnaire and Edinburgh Postnatal Depression Scale. J Affect Disord. 2008;108(3):251-62.

30. Connery HS, Albright BB, Rodolico JM. Adolescent substance use and unplanned pregnancy: strategies for risk reduction. Obstet Gynecol Clin. 2014;41(2):191-203.

31. Cutler JL. Kaplan and Sadock's synopsis of psychiatry. J Psychiatr Pract ${ }^{\circledR}$. 2016;22(1):68-9.

32. Coleman PK, Coyle CT, Shuping M, Rue VM. Induced abortion and anxiety, mood, and substance abuse disorders: isolating the effects of abortion in the national comorbidity survey. J Psychiatr Res. 2009;43(8):770-6.
33. Jebena MG, Taha M, Nakajima M, Lemieux A, Lemessa F, Hoffman R, Tesfaye M, Belachew T, Workineh N, Kebede E. Household food insecurity and mental distress among pregnant women in Southwestern Ethiopia: a cross sectional study design. BMC Pregnancy Childbirth. 2015;15(1):250.

34. Geisner IM, Larimer ME, Neighbors $C$. The relationship among alcohol use, related problems, and symptoms of psychological distress: gender as a moderator in a college sample. Addict Behav. 2004;29(5):843-8.

\section{Publisher's Note}

Springer Nature remains neutral with regard to jurisdictional claims in published maps and institutional affiliations.
Ready to submit your research? Choose BMC and benefit from:

- fast, convenient online submission

- thorough peer review by experienced researchers in your field

- rapid publication on acceptance

- support for research data, including large and complex data types

- gold Open Access which fosters wider collaboration and increased citations

- maximum visibility for your research: over $100 \mathrm{M}$ website views per year

At BMC, research is always in progress.

Learn more biomedcentral.com/submissions 